\title{
Subacute compressive myelopathy secondary to extramedullary hematopoiesis
}

Mielopatia subaguda compressiva secundária a hematopoiese extramedular

Paulo Victor Sgobbi de Souza, Wladimir Bocca Vieira de Rezende Pinto, José Luiz Pedroso, Orlando Graziani Povoas Barsottini

A 25-year-old man presented with subacute onset paraparesis with sphincter disturbance. His past medical history unvealed $\beta$-thalassemia intermedia (compound heterozygote IVS 1-5) and hereditary persistence of fetal hemoglobin type 2. His neurological examination disclosed a complete spinal cord syndrome without clear thoracic sensory level. Spinal cord imaging showed severe thoracic spinal stenosis secondary to paraspinal extramedullary hematopoiesis (Figure). Spinal cord compression is a leading cause of myelopathy in patients with multiple progressive paravertebral masses in chronic extramedullary hematopoiesis ${ }^{1}$, described in hereditary hemoglobinopathies, lymphoproliferative disorders, myelofibrosis and polycythemia vera ${ }^{2}$.
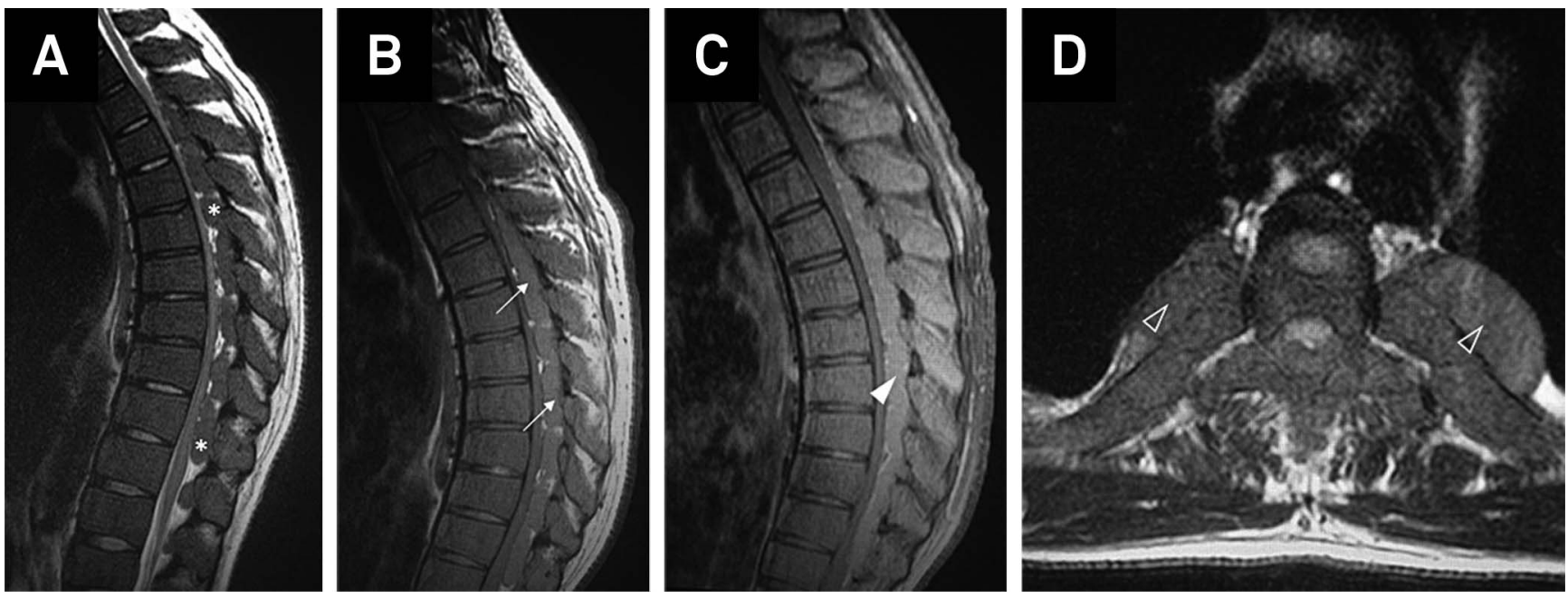

Figure. Non-contrast-enhanced sagittal MRI of the spine at thoracic level disclosing multiple solid masses in the paravertebral spine with intermediate signal on T2-weighted (A; asterisks) and on T1-weighted images (B; arrows). Contrast-enhanced T1weighted sagittal MRI of the spine showing enhancement of the solid masses described in A and B (C; filled arrowhead). Axial T2weighted MRI of the spine evinced severe thoracic spinal stenosis and multiple paravertebral masses (D; non-filled arrowhead).

1. Haidar R, Mhaidli H, Taher AT. Paraspinal extramedullary hematopoiesis in patients with thalassemia intermedia. Eur Spine $J$ 2010;19:871-878.
2. Haidar R, Mhaidli H, Musallam KM, Taher AT. The spine in betathalassemia syndromes. Spine 2012;37:334-339. 